\title{
ENTREVISTA A MAURY MARCANO, DIRECTORA DEL DOCUMENTAL COMO DIOS NOS TRAJO ${ }^{1}$
}

\author{
Ana María Díaz-Marcos² y Luis Alfonso Meléndez ${ }^{3}$
}

Esta entrevista tuvo lugar en el Festival del Cine del Mundo de Montreal el día 30 de agosto del 2014. Ana María Díaz Marcos y Luis Alfonso Meléndez entrevistaron en los pasillos del festival a la escritora y directora de cine Maury Marcano, venezolana afincada en Buenos Aires. "Como Dios Nos Trajo" (2014) es su primer documental y explora la experiencia de las mujeres que trabajan en los clubs de striptease en Caracas y Buenos Aires.

L.A.M. Nos encontramos aquí en el festival de cine de Montreal, al que llevamos asistiendo muchos años y, esta vez, acompañados de la profesora Ana Díaz Marcos, para entrevistar a la directora venezolana Maury Marcano quien acaba de presentar una obra verdaderamente extraordinaria como parte de este festival. Ana, saliste hace un momento de ver esta película.

A.M.D.M. Sí, en primer lugar yo quería felicitar a Maury por su honestidad y por la valentía con que se ha atrevido a abordar un tema tan espinoso. El documental gira en torno a las vidas y experiencias de las mujeres que trabajan haciendo striptease, pero nos presenta también otras problemáticas relacionadas con la mirada masculina o la explotación del cuerpo de la mujer por el patriarcado. Todo ello se cuenta desde una perspectiva autobiográfica y cotidiana, con el coraje

\footnotetext{
${ }^{1}$ Fecha de recepción: 04/07/2014.

Fecha de aceptación: 26/07/2014.

${ }^{2}$ Profesora de la Universidad de Connecticut, Estados Unidos; $\triangle$ ana_maria.marcos@uconn.edu.

${ }^{3}$ Periodista en Radio Vieques, Puerto Rico; $₫$ luisalfonso.melendez2@ymail.com.
} 
implícito en ponerse al mismo tiempo delante y detrás de la cámara. El documental pone énfasis en la vida de mujeres reales, las bailarinas exóticas, que no son interpretadas por actrices profesionales. El filme ha suscitado un número considerable de preguntas en el debate que ha tenido lugar tras la proyección. Me gustaría saber qué hilos y puertas abiertas ha dejado este documental que te hubiera gustado explorar o qué cosas has "cortado" en el producto final. Tú misma has dicho que habías eliminado una parte centrada en el vestuario y los tipos de danza que llevan a cabo las bailarinas. ¿Qué otras preguntas han quedado sin responder o te gustaría abordar en el futuro?

“Como Dios Nos Trajo" es mi primer documental. Respondiendo a tu pregunta, al principio a mí me interesaba mucho el performance de las mujeres, los disfraces, la simbología, el erotismo, el burlesque, cómo nosotros podíamos hacer de ello un arte y un juego: el juego de la seducción. Una vez que me metí en este terreno espinoso me di cuenta de que no tenía tanto glamour como yo estaba buscando y me centré más en las historias reales de las chicas y mi propia historia y ahí me fueron interesando otras cosas. Hoy en día me hago muchas preguntas sobre otros asuntos que colindan el tema que tratamos en el documental. Sobre la prostitución y la trata de blancas, sobre todo sobre la prostitución, porque hay demasiadas variantes a todos los niveles: está la prostituta de alto nivel, la del cabaret, la de la calle, la que ha sido secuestrada. Son muchísimas y muy diferentes maneras de trabajar, si podemos considerar que la prostitución se trata de un trabajo. También me interesa saber cómo afronta cada país esta problemática y cuál es el marco legal. En Latinoamérica no tenemos un marco legal muy fuerte y las mujeres están en una posición muy vulnerable, no solo ante el cliente sino frente al chulo, el cafiolo, el que maneja su oficio. Estos son temas muy delicados sobre los que me hago muchas preguntas y no sé si después de esta película y en un futuro cercano me voy a atrever a abordarlos realizando otro trabajo sobre este tema que es todavía más delicado. Yo vi una película maravillosa mientras estaba haciendo "Como Dios Nos Trajo" que se titula Whore ("Puta", 1991) y el filme plantea una mirada sobre la prostitución como problema global. Por otro lado, al mudarme a Buenos Aires empecé a recibir información sobre la trata de blancas en Latinoamérica. Soy muy sensible a este tema y me preocupa mucho 
que las mujeres desaparezcan, se las secuestre y estén durante años retenidas y trabajando como objetos sexuales sin quererlo ni tener la posibilidad de escapar de ese mundo. Esta realidad me entristece muchísimo y me pregunto constantemente qué hay en la mujer como para generar en el hombre tanta violencia hacia ella. Yo todavía no logro responderme a esto pero es, definitivamente, una de las grandes preguntas de mi vida, afortunadamente sin haber sido una víctima. Yo, en cambio, he tenido libertad: hice este documental porque quise y lo cerré cuando quise también y me considero afortunada por ello.

A.M.D.M. Maury, al final de la película hay un momento en el que tú misma te planteas, con absoluta honestidad, que sientes que de alguna manera estás participando en la explotación si utilizas a las otras mujeres para explorar la fantasía de la que tú partes (la idea de que toda mujer sueña verse como una poderosa bailarina de striptease) para explorar tu propia identidad. Tu documental puede leerse también como una historia de crecimiento $\mathrm{y}$, al final, cuando tú te decides a bailar creas una magnífica escena en la que te presentas como un dictador y construyes una identidad claramente performativa. Para el espectador es obvio que no se trata ya del "tú" genuino y autobiográfico de la película y, en ese momento, cuestionas ante el público la fantasía de la que partiste: "no me sentí poderosa, sino que me sentí vulnerable." En ese momento pasas de estar detrás a colocarte delante de la cámara. ¿En qué medida implica esto un reconocimiento de que esa realidad que te parecía tan glamourosa es, quizás, todo lo contrario?

Precisamente cuando estaba iniciando la película sentía que, de algún modo, mi sensualidad y mi sexualidad implicaban un poder sobre el hombre, el poder de provocar, también el poder de decir que no, de decir hasta dónde. Cuando tú entras a ese mundo te das cuenta de que, como decía en la película, el poder lo tiene el hombre cuando paga y se siente con derecho a hacer lo que desee con ese cuerpo hasta donde se le permita en ese momento. Ahí uno deja de sentirse poderoso y empieza a sentirse realmente indefenso. Obviamente mi vulnerabilidad era bastante ingenua en comparación con lo que puede ser el mundo real de una stripper o una prostituta o de alguien que labure con 
su cuerpo en general y pienso incluso en las modelos. De alguna forma yo me subí allí e igual me sentí frágil, no era en absoluto esa mujer poderosa que tenía el control sobre los hombres porque me estaba quitando la ropa, más bien al revés. Sentí que estaba mostrándome y que, al ponerme en esa posición, le estaba dando armas a los demás para controlarme y eso fue duro y por eso mismo quise exponerlo también.

A.M.D.M. Una de las preguntas que yo te hacía después de asistir a la proyección era si las bailarinas tenían la libertad de crear su propia coreografía o elegir la música porque, verdaderamente, algo que llama la atención a quienes no estamos cercanos a ese mundo del striptease es ver hasta qué punto ese performance busca y se pliega a una mirada que es decididamente masculina. El disfraz de colegiala es un buen ejemplo de ello y pienso si, en tu trabajo de campo, te encontraste con que también había mujeres que asistían a esos espectáculos como a otro tipo más de performance artístico o si existía algún otro espectáculo menos complaciente donde no fuera tan obvio que la bailarina y su exhibición reclaman exclusivamente la mirada heterosexual masculina. ¿Quieres compartir algo a este respecto?

Sí, absolutamente. Yo creo que últimamente tanto mujeres como hombres aprecian el arte del erotismo y ese erotismo es susceptible de convertirse en arte. De hecho, eso era lo que yo estaba buscando al principio. Me encantan las mujeres que bailan y el modo en que manejan su sensualidad porque lo considero algo hermoso. Desde siempre la mujer ha sido pintada y fotografiada en su desnudez o de una forma erótica en función del arte. Entonces siento que los prejuicios se están diluyendo pero también están insertos en una sociedad donde hay una realidad complicada para muchas mujeres. Quizás yo estaba buscando una realidad "idealizada" del primer mundo donde artistas en el ámbito de lo erótico pudieran ser respetadas por su trabajo sin sentirse tan frágiles. Pero yo no encontré eso o, al menos, no lo encontré en Buenos Aires. Tampoco recorrí las calles y puede ser que exista, ¿por qué no? Para concluir siento que, definitivamente, la actividad performativa de la mujer expresando su sensualidad, que es una parte inherente de su ser, 
es arte. Ahora bien, lo que haga el consumidor con eso o el objetivo que tiene el baile en sí puede muy bien ser otra cosa dependiendo del contexto en que se esté desarrollando.

L.A.M. La reacción de público ha sido espectacular en las dos proyecciones a las que hemos asistido. ¿Cómo ha sido tu lectura de ese recibimiento por parte del público y qué significa para ti participar en un festival como éste, el festival de Cine del Mundo de Montreal?

Yo estoy inmensamente feliz porque esto nació como un proyecto de escuela. La idea era realizar un cortometraje de 20 minutos como máximo que iba a limitarse a una proyección académica y ahora, cinco años más tarde, estoy acá después de mucho trabajo. El documental ya se ha presentado en La Habana, en Guadalajara (México), aquí en Montreal y ahora va para Nueva York y esto ha superado en mucho todas mis expectativas. Estoy muy contenta de la respuesta del público porque tenía miedo de ser juzgada o malinterpretada o que se pudiera pensar que yo estaba de acuerdo con la explotación femenina. No es cierto en absoluto y traté de dejar muy claro esto porque me preocupaba. Siento que la gente lo percibió así, se dio cuenta de esto y el objetivo de comunicar lo que yo quise con la película se cumplió. Creo que una de las cosas más importantes para un comunicador o cineasta es que el público entienda y le llegue el mensaje que uno quiere compartir.

L.A.M. ¿Tienes alguna anécdota 0 algún aspecto específico de la reacción o las preguntas del público que te haya tocado especialmente o alguna impresión sobre este festival que quieras compartir con otros colegas del entorno del cine?

He visto muy pocas películas en Montreal y me gustaría ver más, pero me han encantado algunas que tratan la problemática de género. He visto una película iraní fantástica, No Land's Song (2014), que se estrenó oficialmente ayer en este festival, y sentí completamente su historia. Cuando me gradué de la universidad yo decía que quería cambiar el mundo y que para eso estudiaba periodismo pero luego, cuando salí a la calle, me di cuenta de que cambiar al mundo era una tarea demasiado grande. Sin embargo, una persona que escoge ser un comunicador, sí que puede cambiar algunas cosas. Esta película 
iraní responde al hecho de que probablemente no hay ningún político que pueda resolver el problema de la discriminación de las mujeres en los países musulmanes. Pero si el filme logra proyectarse no solo internacionalmente, sino en Irán y las mujeres iraníes pueden verlo, podría desencadenar una revolución haciendo que ellas se empoderen de su causa y cambien de alguna manera su sociedad. Eso es lo fascinante de los festivales de cine. En estos festivales internacionales uno comparte un pedazo de su cultura y también los problemas que uno tiene y termina dándose cuenta de que los problemas son los mismos y que todos somos los mismos aunque lo vivamos y afrontemos de diferente manera, pero todavía estamos en la lucha. Este es mi grano de arena y espero que mi película haya aportado algo a la comprensión de los problemas de género en Latinoamérica de la misma forma que la película de Irán me hizo llorar y reflexionar a mí. Váyanla a ver.

A.M.D.M. Mi impresión es que el público no duda en ningún momento de tu sinceridad. "Como Dios Nos Trajo" problematiza muchas cuestiones y supone una importante aportación a debates sobre cuestiones tan complejas como los papeles de género, la explotación femenina y la objetivación de la mujer en el mundo hispánico y en la cultura occidental moderna en general. 